\title{
The harmonic reduction techniques in shunt active power filter when integrated with non-conventional energy sources
}

\author{
Kambhampati Venkata Govardhan Rao ${ }^{1}$, Malligunta Kiran Kumar ${ }^{2}$ \\ ${ }^{1}$ Department of Electrical and Electronics Engineering, Scholar in Electrical and Electronics Engineering \\ Koneru Lakshmaiah Education Foundation, Vaddeswaram, Andhra Pradesh, India \\ ${ }^{2}$ Department of Electrical and Electronics Engineering, Faculty in Electrical and Electronics Engineering \\ Koneru Lakshmaiah Education Foundation, Vaddeswaram, Andhra Pradesh, India
}

\begin{tabular}{l} 
Article Info \\
Article history: \\
Received Sep 27, 2021 \\
Revised Dec 9, 2021 \\
Accepted Jan 11, 2022 \\
\hline Keywords: \\
Active power filter \\
ANN controller \\
Harmonic current reduction \\
Maximum power point tracking \\
Voltage source converter with \\
four leg operation
\end{tabular}

\begin{abstract}
The article covers the control techniques of shunt active filters using switching devices using artificial neural network (ANN) Theory. The basic idea is to achieve perfect disturbance minimization in both steady and transient states. The paper talks about a four-legged converter with a voltage source that can adjust for biased currents and harmonic elements caused by non-linear loads. A shunt connected active filter is used to minimise harmonic currents. The new proposed ANN controller for the improvement of percent total harmonic distortion (THD) is in comparison. The entire power filter concept is based on a MATLAB-modeled with ANN controller. The proposed circuit in this research is studied under various operating situations and simulated, demonstrating the system's potential.
\end{abstract}

This is an open access article under the CC BY-SA license.

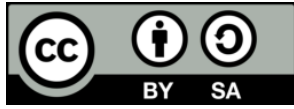

\section{Corresponding Author:}

\section{Malligunta Kiran Kumar}

Department of Electrical and Electronics Engineering, Faculty in Electrical and Electronics Engineering Koneru Lakshmaiah Education Foundation

Vaddeswaram, Guntur-522502, Andhra Pradesh, India

Email: kiran.malligunta@gmail.com

\section{INTRODUCTION}

A large number of domestic and business electrical loads have recently been fused into facility grids. It causes problems with power quality [1], [2]. Thyristor rectifiers, when connected to the facility grid, create many harmonics for the growing number of loads that do not respect ohm's law, such as diodes. Harmonics create voltage distortions, grid losses, and poor load operation as a result of this. As a result, IEEE 519 standards [3] are recommended at the grid to manage harmonic currents caused by rapid load variations. The shunt power filter (SPF) is made up of specially tuned LC and high band pass filter settings. These are simple to use and provide a cost-effective solution for harmonics. Furthermore, the effectiveness of shunt filters is mostly determined by grid impedance, which might cause shunt resonance phenomena with the grid, which is not desirable. Harmonic reduction results in higher efficiency of power semiconductor devices [4], [5]. The voltage source inverter is made up of the shunt active power filter (SAPF) voltage source inverter (VSI). Voltage disturbances in the power system are caused by irregular power generation. The algorithmic control method using artificial neural network (ANN) and proportional integral (PI) controllers is explained in this work. APFs, like PI (for linear analysis) or predictive (non-linear) controllers, are generally controlled and particular. In general, predictive controllers are close to the current power system. The current methods demonstrate how to increase APF performance under dynamic settings. It will be capable of precisely executing the reference signal for the current parameter while maintaining direct current (DC) 
voltage [5], [6]. This control approach illustrates how to handle multivariate features in electric drive applications. It provides a straightforward way to compensate for dead time and replace pulse width modulation (PWM). The advantage of this approach is that it is suitable for all APF applications because the output parameters are known.

\section{MODEL OF A FOUR-LEG PWM-VI CONVERTER}

The non-traditional energy producing system is depicted in Figure 1, along with a typical distribution system. It consists of several non-conventional energy production units, such as wind and solar energy, and distributes power created to small businesses and homes [6], [7]. Battery banks must be employed for long-term energy storage. Alternating current AC/AC and DC/AC static pulse width modulation converters are used in these grids [8]. These converters employ the maximum power point tracking (MPPT) approach to get great efficiency from solar and wind energy [9]. SAPF is connected to point of common coupling (PCC) in a shunt configuration to reduce current wave disturbances and imbalance. For the basis order depicted in Figure 2, SAPF consists of a PWM converter and a harmonic filter [10], [11]. It has an equivalent impedance of $\mathrm{Zs}$, an impedance of $\mathrm{Zf}$ at the output ripple filter, and an impedance of $\mathrm{ZL}$ at the load terminals.

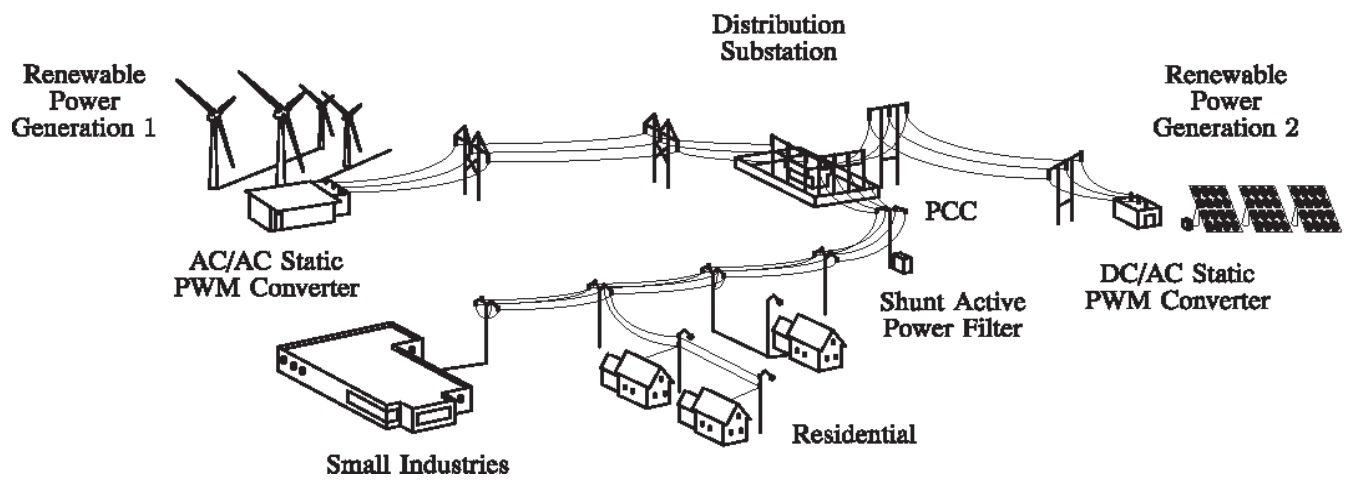

Figure 1. Parallel connected power filter for hybrid energy generation

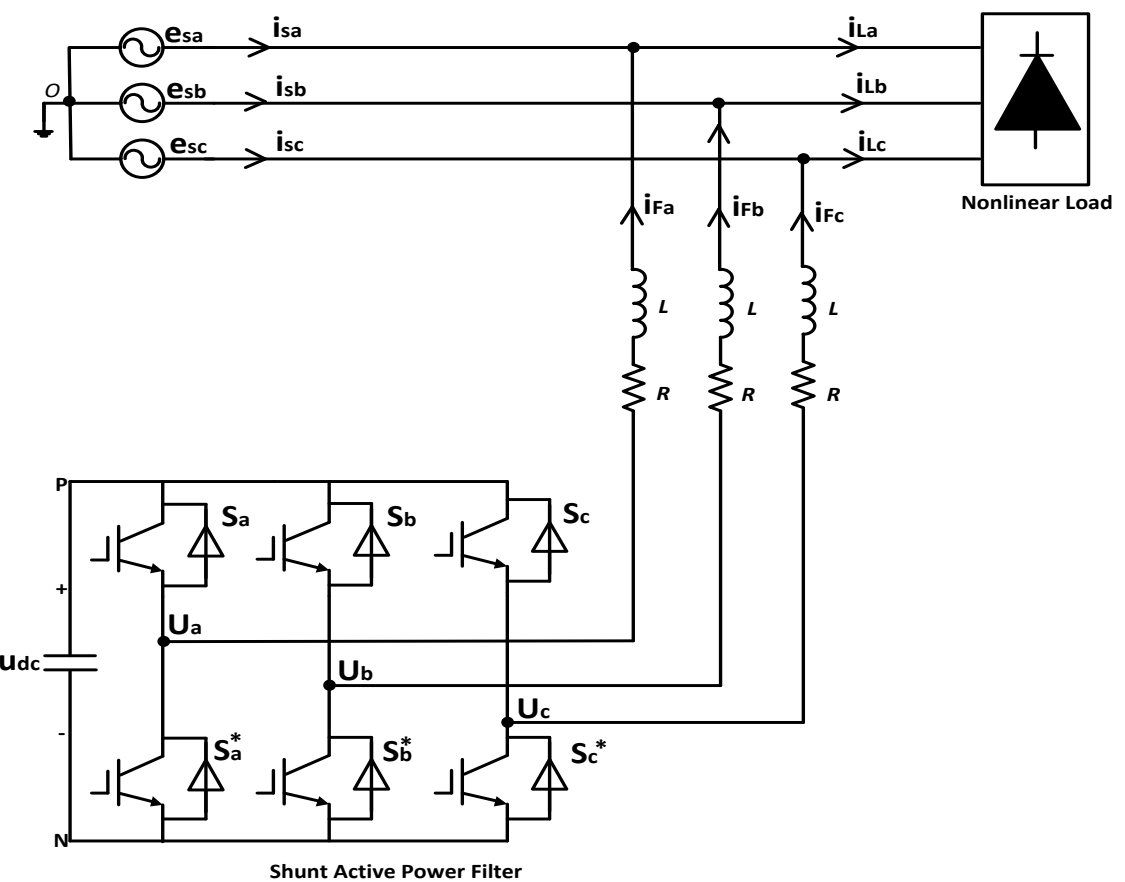

Figure 2. For two 3-SAPF, an analogous circuit has been proposed 
The study of the PWM converter [12] is shown in Figure 3. It's comparable to a three-phase converter with the fourth leg connected to a neutral bus. By increasing the frequency at which switches are turned on and off, this architecture enhances the control litheness and voltage quality that is productive. In terms of frequency of switch on and off states, The voltage is calculated in $\mathrm{x}$ volts, which is determined from the neutral point $n$.

$$
v_{x n}=S_{x}-S_{n} v_{d c}, x=u, v, w, n
$$

In terms of mathematical analysis, the corresponding circuit is shown in Figure 2.

$$
V_{0}=v_{x n}-R_{e q} i_{0}-L_{e q} \frac{d i_{o}}{d t}
$$

Where $\mathrm{R}_{\mathrm{eq}}$ and $\mathrm{L}_{\mathrm{eq}}$ are the impedance of the thevenin at the second port. As a result, utilising Thevenin's phenomena, equivalent impedance can be calculated algebraically as (3).

$$
z_{e q}=\frac{Z_{s} Z_{L}}{Z_{s}+Z_{L}}+Z_{f}=Z_{s}+Z_{f}
$$

The impedance equivalent value is omitted, resulting in $\mathrm{ZL} \gg \mathrm{Zs}$ and a reactance linked in series value of $3-7 \%$ p.u., which is appropriate for a practical system. As a result of (2).

$$
R \text { eq }=R f \text { and } L \text { eq }=L s+L f \text {. }
$$

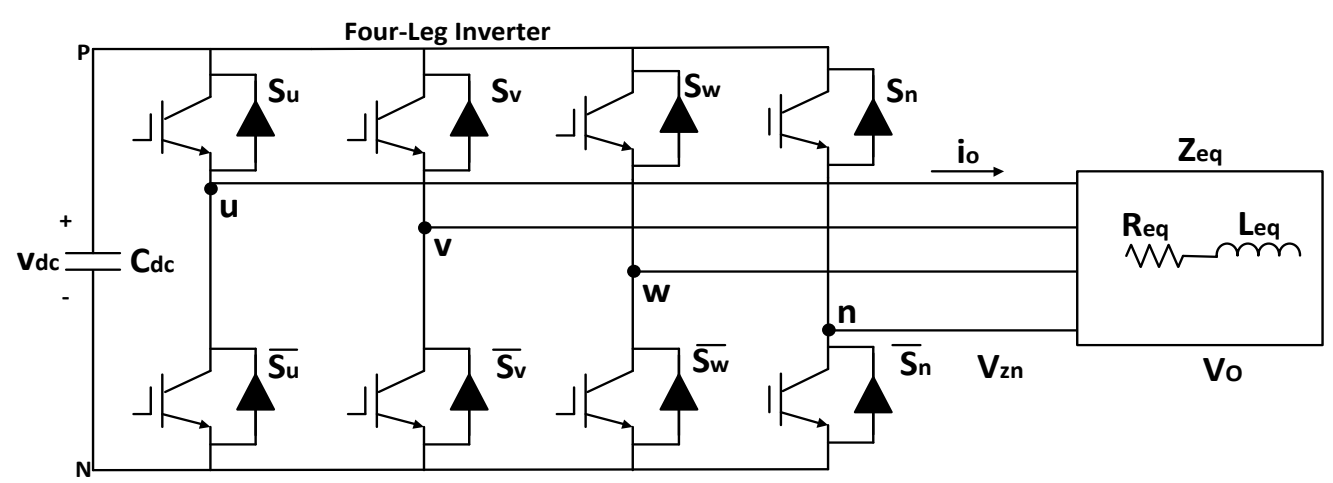

Figure 3. Pulse width modulation for a four-leg circuit with two levels

\section{CURRENT CONTROL DEVELOPMENT WITH DIGITAL TECHNOLOGY}

The proposed current control strategy using digital technology is depicted in Figure 4. It outlines a control algorithm that is fed into a microprocessor as an input. To illustrate time delay and its assumptions, discrete mathematics is used. It uses the most switching structural information available to apply to the converter.

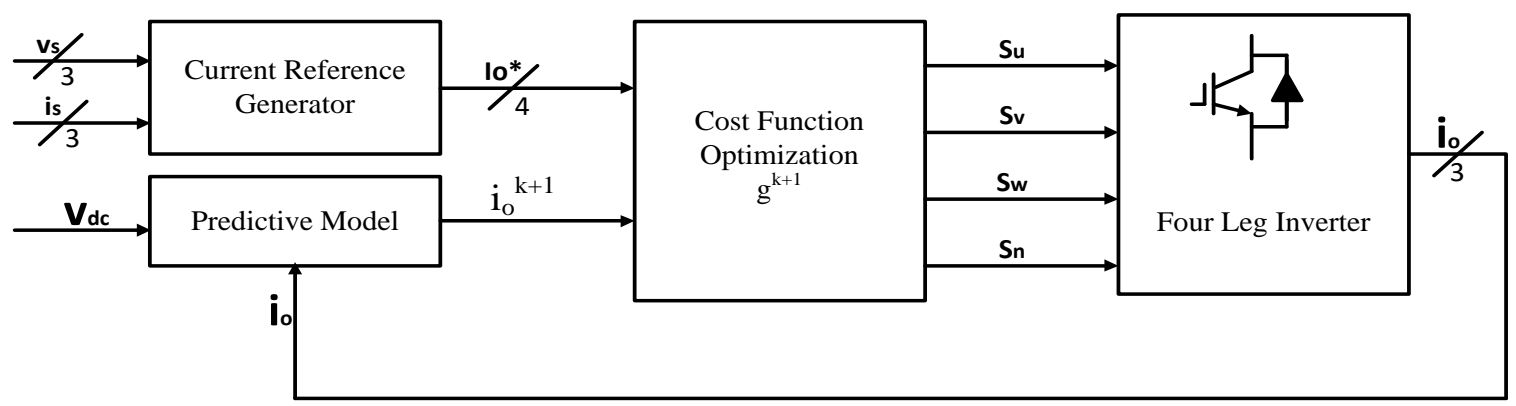

Figure 4. Digital technology was proposed for current control 


\subsection{Generator of current reference}

This is a unit that will not be capable of reflecting current technology, that is under a saturated load. The system voltages and load currents are measured using this method. As a result, the output current profile of the signals at the neutral point terminal and the load terminal is developed.

\subsection{Model of prediction}

It functions in a discrete time frame. It's a cyclic vector equation that represents a forecasting model. It can construct a sample time $\mathrm{Ts}$ and assume following states at any instant $[\mathrm{k}+1] \mathrm{T}_{\mathrm{s}}$ knowing the frequency of the converter's on and off phases at simultaneous kTs. All approximations are in first order because the equations are in a single order ripple filter.

$$
\frac{d x}{d t}=\frac{x[k+1]-x[k]}{T_{S}}
$$

The current at port 2 and its algorithm calculated 16 possible predicted data from (2) and (4).

$$
i_{0}[k+1]=\frac{T_{S}}{L_{e q}}\left(v_{x n}[K]-v_{0}[K]\right)+\left(1-\frac{R_{e q} T_{s}}{L_{e q}}\right) i_{0}[K]
$$

The voltage at the input port, $\mathrm{Vo}_{\mathrm{o}}$, and the voltage at the conversion port, $\mathrm{V}_{\mathrm{xn}}$, are required to anticipate current at the output port, $\dot{i}_{\mathrm{o}}$ at $(\mathrm{k}+1)$, as shown in (5). This algorithm is used to determine all sixteen values involved in various groups.

\subsection{Optimization of the cost function}

The 16 anticipated readings for $\mathrm{i}_{\mathrm{o}}[\mathrm{k}+1]$ are contrasted to the precedent using a cost function $\mathrm{g}$ : to determine the best duty cycle for the power converter.

$$
\begin{aligned}
& g(k+1)=\left[i_{o u}^{*}(k+1)-i_{o u}(k+1)\right]^{2}+\left[i_{o v}^{*}(k+1)-i_{o v}(k+1)\right]^{2} \\
& +\left[i_{o w}^{*}(k+1)-i_{o w}(k+1)\right]^{2}+\left[i_{o n}^{*}(k+1)-i_{o n}(k+1)\right]^{2}
\end{aligned}
$$

The output current (io) matches the standard current ( $\left.i^{*} \mathrm{o}\right)$ when $g=0$. As a result, the improvement aim for the value/price combination is to get the $\mathrm{g}$ value as close to zero as possible. At the next sample state, the voltage vector $v_{x}$ with the lowest cost function is chosen and used. From the 16 alternative function values at each sample state, the switching state that offers the lowest price of $g$ is chosen. The algorithm selects the smallest switching state and applies it to the converter throughout the $\mathrm{k}+1$ stage.

\section{PRODUCTION OF CURRENT REFERENCE SIGNAL}

With the dq approach, the reference signals for the current parameter are provided as input from the reference generator. It has a fast and accurate signal tracking capacity. It eliminates voltage fluctuations, which have a negative impact on compensating performance [13], [14]. Figure 5 shows the reference signals for equivalent currents at the load terminal. The current reference generator creates current signals to decrease current imbalance, disturbances in current, and reactive power. The apparent power applied by an active power filter to a load terminal is expressed in terms of $\sin (\mathrm{L})$ and $(\mathrm{THD}(\mathrm{L}))$ as (7).

$$
\frac{S_{A P F}}{S_{L}}=\frac{\sqrt{\sin \emptyset_{(L)}+T H D_{(L)}^{2}}}{\sqrt{1+T H D_{(L)}^{2}}}
$$

The peak current due to harmonics, given as the square of the fs, is the THD of a load, according to the (7). The current due to the distortion component will be reduced to half of the converter's on and off cycle frequency [14], [15]. The dq-based approach employs a rotating reference frame. The reference signals $\sin (w t)$ and $\cos (w t)$ were coordinated, and the phase of the reactive current elements was changed by $90^{\circ}$. all of which were acquired from a synchronous coordinate system. When the phase locked loop PLL voltage is totally disrupted, pure sinusoidal waveforms can be generated. We can reduce tracking errors as well as phase voltage unbalancing, harmonics [16], [17], which can arise during measurement. The link between the important currents $i \operatorname{Lx}(\mathrm{t})(\mathrm{x}=\mathrm{u}, \mathrm{v}, \mathrm{w})$ and their dq components is seen in (8) (id and iq). 


$$
\left[\begin{array}{l}
i_{d} \\
i_{q}
\end{array}\right]=\sqrt{\frac{2}{3}}\left[\begin{array}{cc}
\sin \omega t & \cos \omega t \\
-\cos \omega t & \sin \omega t
\end{array}\right]\left[\begin{array}{ccc}
1 & \frac{-1}{2} & \frac{-1}{2} \\
0 & \frac{\sqrt{3}}{2} & \frac{-\sqrt{3}}{2}
\end{array}\right]\left[\begin{array}{l}
i_{L u} \\
i_{L v} \\
i_{L w}
\end{array}\right]
$$

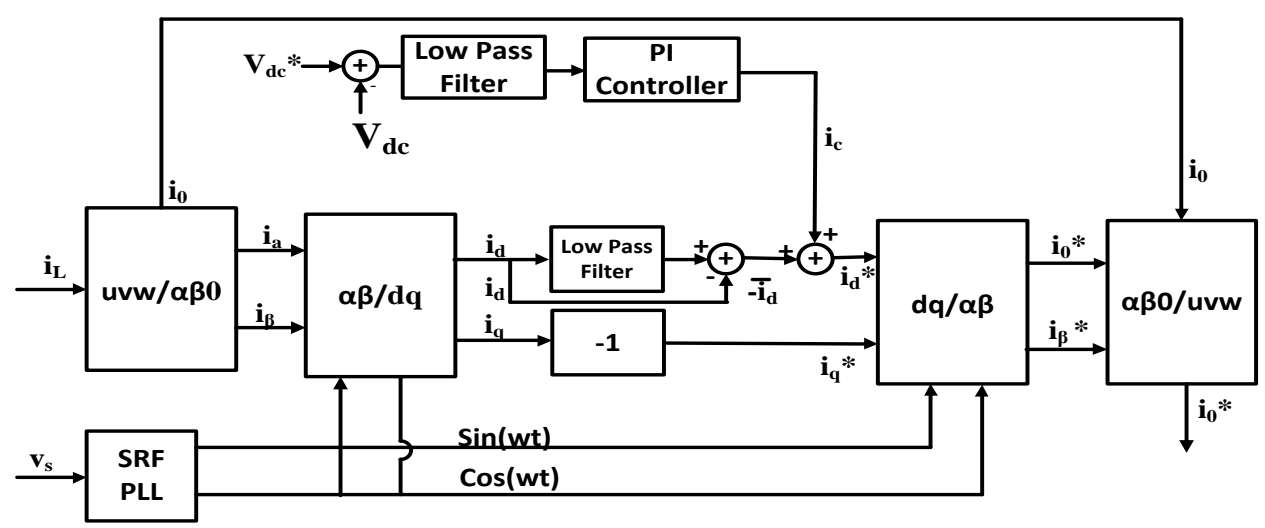

Figure 5. Using a dq-based approach as a current reference generator

Between currents at phase and the equivalent AC and DC components of Iq, there is an $180^{\circ}$ phase shift. To keep the DC voltage constant, the converter's reference current and amplitude must be changed by summing a lively power reference signal. In part 4.1, it will go through everything in detail. The reverse Park and Clark transformation, as illustrated in, aids in the conversion of id and iq signals to three-phase systems (9).

$$
\left[\begin{array}{l}
i_{o u}^{*} \\
i_{o v}^{*} \\
i_{o w}^{*}
\end{array}\right]=\sqrt{\frac{2}{3}}\left[\begin{array}{ccc}
\frac{1}{\sqrt{2}} & 1 & 0 \\
\frac{1}{\sqrt{2}} & -\frac{1}{2} & \frac{\sqrt{3}}{2} \\
\frac{1}{\sqrt{2}} & -\frac{1}{2} & -\frac{\sqrt{3}}{2}
\end{array}\right] \times\left[\begin{array}{ccc}
1 & 0 & 0 \\
0 & \sin \omega t & -\cos \omega t \\
0 & \cos \omega t & \sin \omega t
\end{array}\right]\left[\begin{array}{l}
i_{0} \\
i_{d}^{*} \\
i_{q}^{*}
\end{array}\right]
$$

The current flow through the neutral of the load will be balanced by keeping the equivalent abrupt value computed from currents at phase, phase shifted by $180^{\circ}$ as seen in the following diagram.

$$
i_{o n}^{*}=-\left(i_{L u}+i_{L v}+i_{L w}\right)
$$

The main merit of the current generator explained using a dq-based method is that it allows the use of a direct controller with DC voltage control. The main disadvantage is that the dq-based current coordinate system algorithm will not organise the current reference second order harmonic component under unbalanced operation. The amplitude of the harmonic generated is determined by the imbalanced load current. It can also produce second and third order harmonics of id and iq, as well as third order harmonic current. Because the load current is devoid of third-order harmonic current, it passes through the load.

\subsection{DC voltage control}

Basic PI controller is used to control DC voltage. The slow reaction of electrolytic capacitors has little effect on current transient responsiveness. As a result, the PI controller can be used to control DC voltage [18], [19]. The voltage profile is corrected until no losses are incurred and it is kept constant.

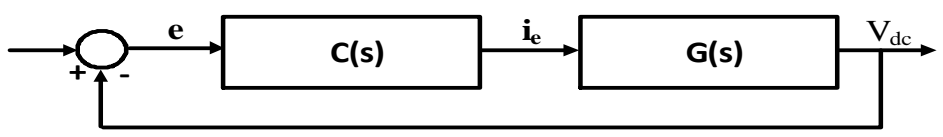

Figure 6. Maintaining the Voltage Profile for DC diagram 
The amplitude of APF in the phase voltage direction is stabilised [20] and absorbs active power. As shown in Figure 6, the applied DC voltage is compared to a constant reference value. With gains $\mathrm{Kp}$ and $\mathrm{Ti}$, the error created is sent to the PI Controller. With DC voltage, the single order controller with PI is fed to the transfer function.

$$
G(s)=\frac{v_{d c}}{i_{c}}=\frac{3}{2} \frac{K_{p} v_{s} \sqrt{2}}{C_{d c} v_{d c}^{*}}
$$

The controller with PI is done in the same way as a closed loop TF and is shown in (12), (13).

$$
\begin{aligned}
& C(s)=K_{p}\left(1+\frac{1}{T_{i} \cdot s}\right) \\
& \frac{v_{d c}}{i_{c}}=\frac{\frac{\omega_{n}^{2}}{a} \cdot(s+a)}{s^{2}+2 \delta \omega_{n} \cdot s+\omega_{n}^{2}}
\end{aligned}
$$

with $\zeta=1$ a critically damped response system is created, Angular speed with natural frequency, $\omega n=2 \pi \cdot 100$ $\mathrm{rad} / \mathrm{s}$, Integral time, $\mathrm{Ti}=1 / \mathrm{a}$ and proportional gain $\mathrm{Kp}$ can be measured using ANN.

$$
\begin{gathered}
\delta=\sqrt{\frac{3}{8} \frac{K_{p} v_{s} \sqrt{2} T_{i}}{C_{d c} v_{d c}^{*}}} \\
\omega_{n}=\sqrt{\frac{3}{2} \frac{K_{p} v_{s} \sqrt{2}}{C_{d c} v_{d c}^{*} T_{i}}}
\end{gathered}
$$

\subsection{Training of $A N N$}

When compared to fuzzy controllers, ANN is more useful because it is more efficient and fault tolerant. To improve control quality, data from hard controllers can be communicated with intelligent controllers utilising ANN [21], [22]. Feed forward neural networks perform the function of the compensation signal generator [23]. It has three layers, with seven neurons in the input layer and twenty-one neurons in the hidden layer (see Figure 7).

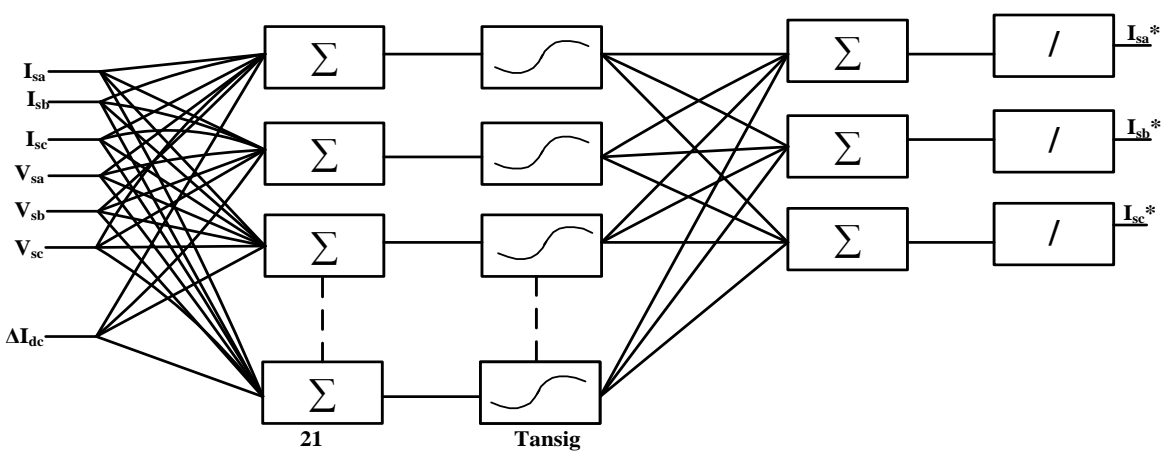

Figure 7. ANN network structure proposed

The output is influenced by the sort of input and how it evolves. As previously stated, the proposed concept consists of seven input neurons. The reference, load voltage, source current, and output for error (PI) controllers are among them. The output of the ANN is based on fundamental reference currents. The hysteresis load current controller consists of switching signals as output.

\section{HARMONIC REDUCTION USING MPPT}

MPPT techniques can also be used to solve the main harmonic problem. The MPPT system stands for maximum power point tracking [24]. MPPT approaches include perturbation and observation [P\&O], hill climbing (HC), fractional voc, and fractional Isc, as well as newer techniques like fuzzy logic, met heuristic algorithms, and ANN. These techniques aid in maintaining consistent precision, doubling tracking speed, and 
converting significant amounts of energy and power. The P\&O approach is the most often utilised MPPT technique in solar systems [25], [26] among all available methods. The P\&O approach aids in maximum power tracking, as well as balancing voltage, current, and power among solar PV modules and assisting in power rise or decrease. The Table 1 provides a detailed examination of several MPPT strategies [27], [28] for reducing THD.

Table 1. Summary of methods in MPPT

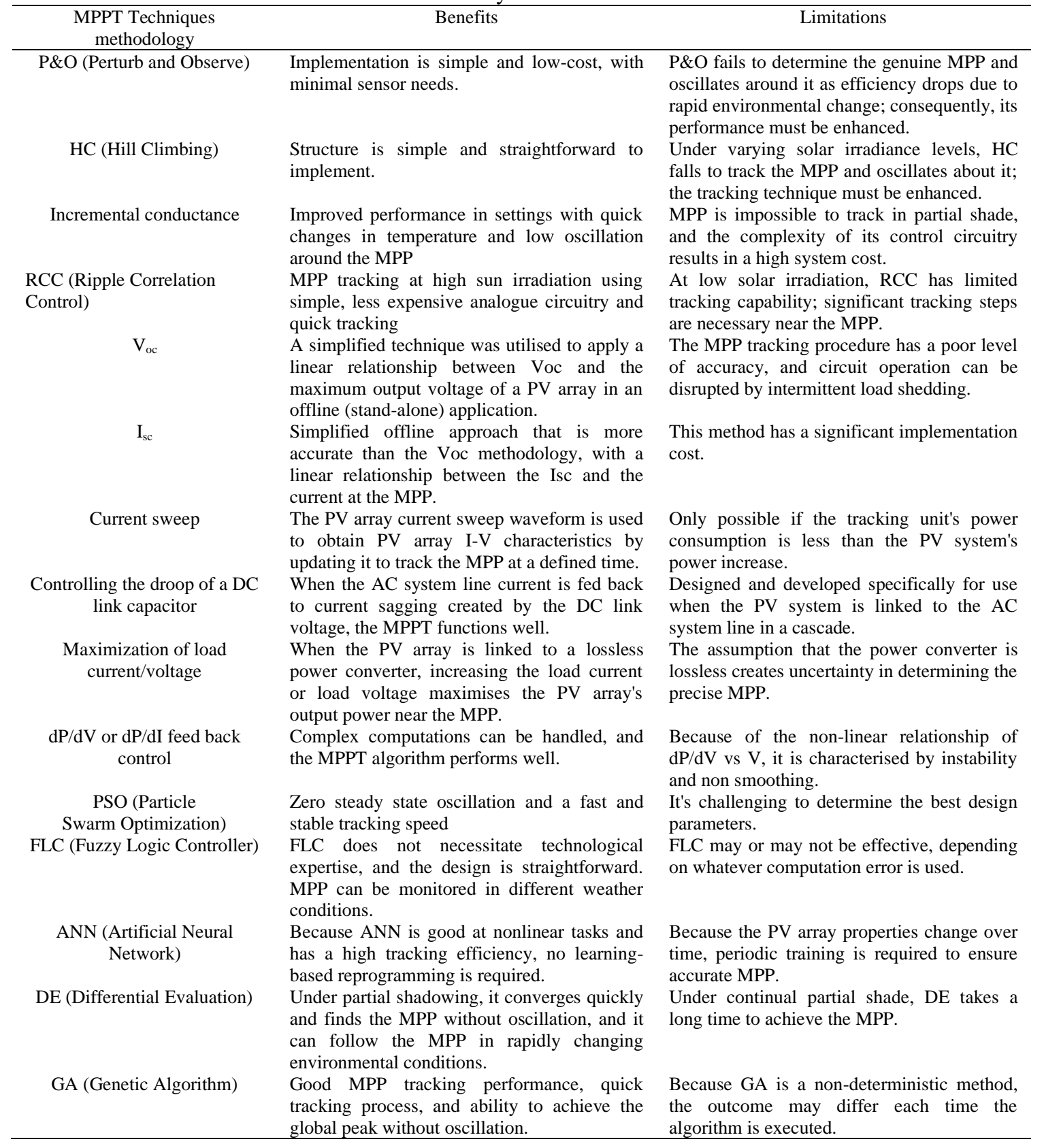

\section{SIMULATION RESULTS}

The simulation results of proposed circuits are displayed in Figure 8. From the Figure 8(a) shows the terminal voltage, Figure 8(b) explain about load at the terminal of current profile, Figure 8(c) explain about Current profile at Active filter terminal, Figure 8(d) displays about Neutral current profile at load terminal, Figure 8(e) shows the Current at neutral terminal, Figure 8(f) displays Current in the system Figure 8(g) gives about Voltage profile at DC converter, and Figure 8(h) Current at the grid. The simulation THD values for the proposed circuit with PI and ANN controller for reduction of harmonic distrortion are shown in 
Figure 9. Figure 9(a) will gives the values of THD in case of PI controller and Figure 9(b) will gives the values of THD in case of ANN controller, same will displayed in the Table 2.
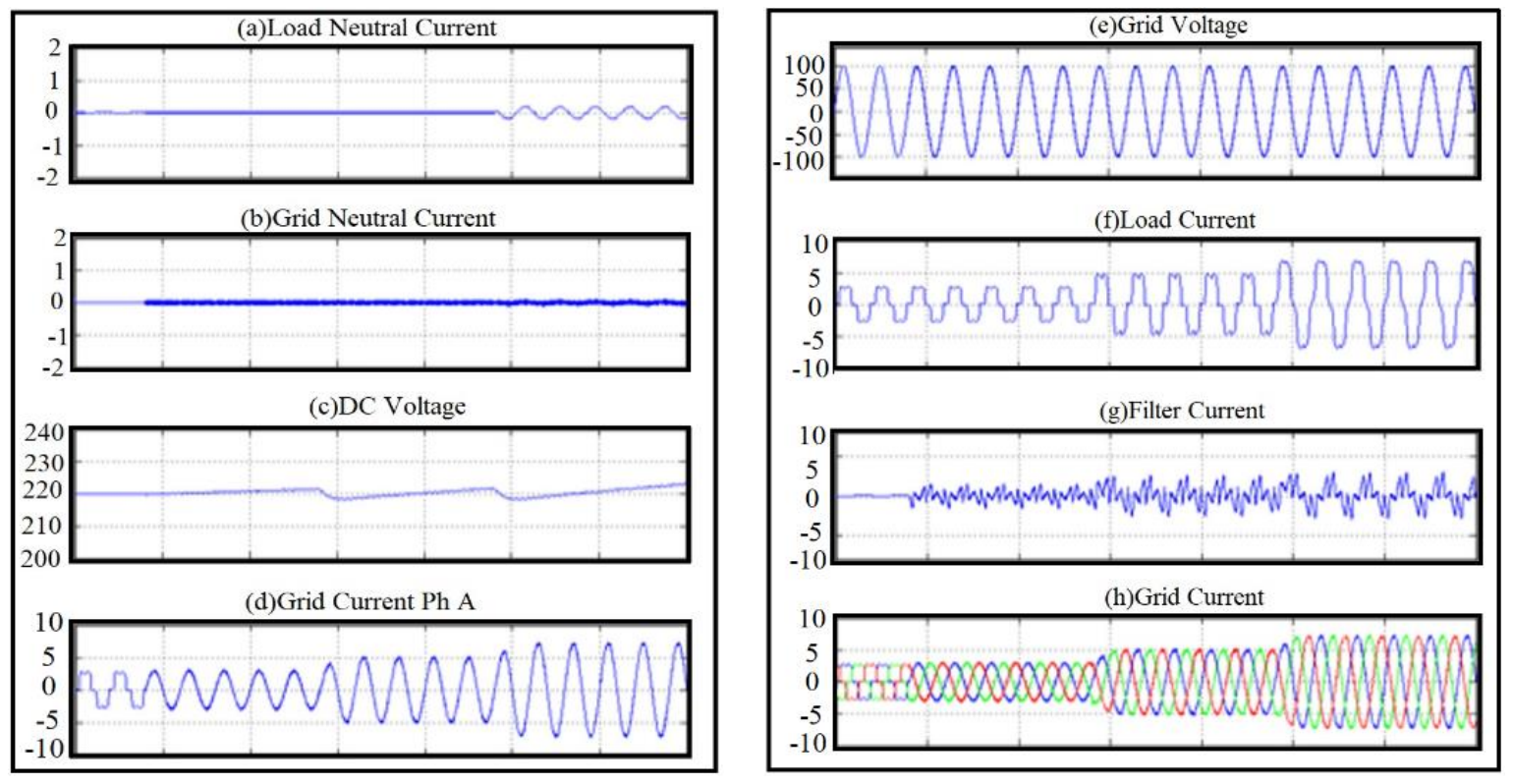

Figure 8. Circuit outputs that have been proposed; (a) voltage at the source terminal; (b) at the load terminal, the current profile; (c) at the active filter terminal, the current profile is displayed; (d) at the load terminal, the current profile is neutral; (e) current flowing via the neutral terminal; (f) currently available in the system; (g) DC converter voltage profile; (h) the current state of the grid

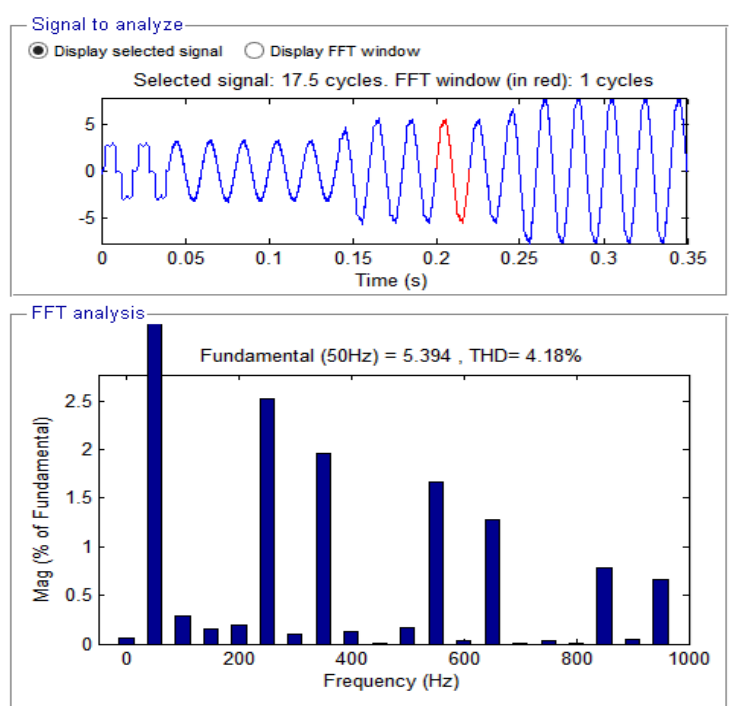

(a)
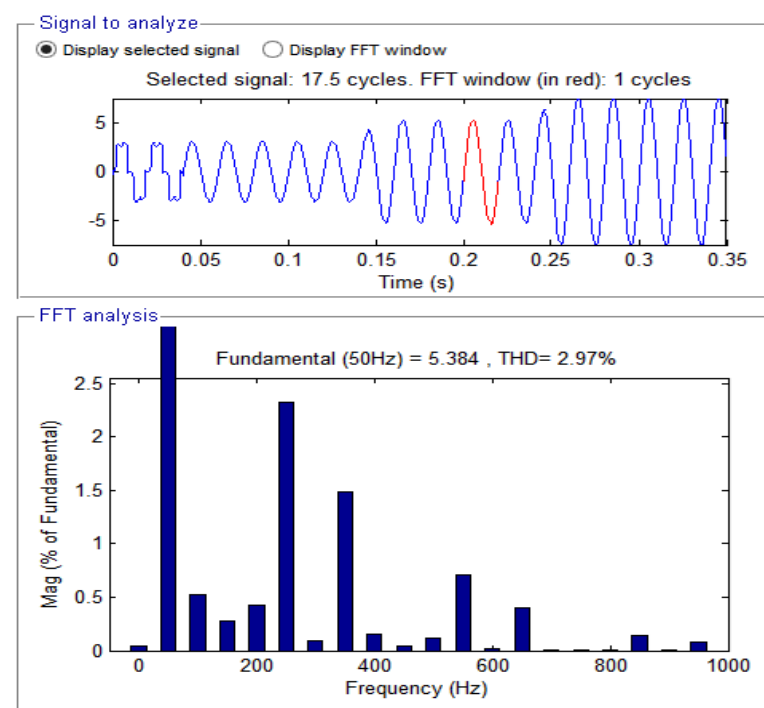

(b)

Figure 9. Values of THD, (a) with a PI controller 4.18 percent and (b) with ANN controller 2.97 percent

Table 2. Total harmonic distortion of current profile at source terminals using PI and ANN (\%)

\begin{tabular}{cccc}
\hline Controller & Nonlinear Load1 & Nonlinear Load2 & Unbalanced Load3 \\
\hline PI & $2.53 \%$ & $4.18 \%$ & $2.75 \%$ \\
ANN & $1.04 \%$ & $2.97 \%$ & $1.75 \%$ \\
\hline
\end{tabular}




\section{CONCLUSION}

The study proposes using SIMULINK to implement SAPF with ANN. The SAPF compensates for harmonics by using a non-linear load. Therefore, it was determined that using PI, the overall harmonic distortion of the current profile at source terminals is 4.18 percent, but using an ANN controller, it is 2.97 percent. It's also been put through its paces under various nonlinear load circumstances, with the results tabulated. As a result of the results obtained, it is concluded that PI is less effective than ANN.

\section{REFERENCES}

[1] J. Rocabert, A. Luna, F. Blaabjerg, and P. Rodríguez, "Control of power converters in AC microgrids," IEEE Transactions on Power Electronics, vol. 27, no. 11, pp. 4734-4749, Nov. 2012, doi: 10.1109/TPEL.2012.2199334.

[2] K. Baig, K. Prudhvi Raj, G. G. Raja Sekhar, T. Vijay Muni, and M. Kiran Kumar, "Power quality enchancement with active power control," Journal of Critical Reviews, vol. 7, no. 9, pp. 739-741, Jun. 2020, doi: 10.31838/jcr.07.09.143.

[3] IEEE Std. 519-2014, "IEEE Recommended Practice and Requirements for Harmonic Control in Electric Power Systems," IEEE Std. 519-2014, vol. 2014. IEEE, 2014, doi: 10.1109/ieeestd.2014.6826459.

[4] A. G. Peter and K. A. Saha, "Comparative study of harmonics reduction and power factor enhancement of six and 12-pulses HVDC system using passive and shunt APFs harmonic filters," in 2018 International Conference on the Domestic Use of Energy, DUE 2018, Apr. 2018, pp. 1-7, doi: 10.23919/DUE.2018.8384395.

[5] V. T. Rama Reddy, T. S. Sai, M. K. Kumar, N. Rajesh, and B. Nagi Reddy, "Harmonic mitigation and power quality enhancement using PV fed series active filter for grid systems," International Journal of Scientific and Technology Research, vol. 9, no. 1, pp. 3004-3009, 2020, Accessed: Jan. 17, 2022. [Online]. Available: www.ijstr.org.

[6] A. K. Roy, G. R. Biswal, and P. Basak, "A Study on Power Quality Improvement by Active Power Filter in Hybrid Sustainable Energy Systems," in 2019 International Conference on Power Electronics, Control and Automation, ICPECA 2019 Proceedings, Nov. 2019, vol. 2019-November, doi: 10.1109/ICPECA47973.2019.8975492.

[7] G. V. S. Babu and V. Ganesh, "Power quality enhancement in distributed energy resources by four leg voltage source converter," in IEEE International Conference on Innovative Mechanisms for Industry Applications, ICIMIA 2017 - Proceedings, Feb. 2017, pp. 327-331, doi: 10.1109/ICIMIA.2017.7975629.

[8] K. Deka, S. Mahapatra, P. K. Bordoloi, and B. Medhi, "Design and testing of a control system for supply side electrical load management," in Proceedings of 2014 1st International Conference on Non Conventional Energy: Search for Clean and Safe Energy, ICONCE 2014, Jan. 2014, pp. 277-281, doi: 10.1109/ICONCE.2014.6808726.

[9] T. Komrska, T. Glasberger, and Z. Peroutka, "Minimum Infinity Norm-Based PWM for Three-Phase Four-Leg Converters," in IEEE International Symposium on Industrial Electronics, Jun. 2019, vol. 2019-June, pp. 902-907, doi: 10.1109/ISIE.2019.8781324.

[10] O. Noureldeen and A. M. A. Ibrahim, "Modeling, implementation and performance analysis of a grid-connected photovoltaic/wind hybrid power system," in Proceedings of 2018 International Conference on Innovative Trends in Computer Engineering, ITCE 2018, Feb. 2018, vol. 2018-March, pp. 296-304, doi: 10.1109/ITCE.2018.8316641.

[11] A. H. Fahad and M. S. Reza, "Single-Phase Shunt Active Power Filter Using Parabolic PWM for Current Control," in Proceedings of 2019 the 7th International Conference on Smart Energy Grid Engineering, SEGE 2019, Aug. 2019, pp. 134-138, doi: 10.1109/SEGE.2019.8859868.

[12] S. Agrawal, S. K. Vaishnav, Ajit, and R. K. Somani, "Active power filter for harmonic mitigation of power quality issues in grid integrated photovoltaic generation system," in 2020 7th International Conference on Signal Processing and Integrated Networks, SPIN 2020, Feb. 2020, pp. 317-321, doi: 10.1109/SPIN48934.2020.9070979.

[13] D. A. Fernandes and S. R. Naidu, "A novel PWM scheme for the 4-leg voltage source converter and its use in dynamic voltage restoration," Jun. 2007, doi: 10.1109/PES.2007.385865.

[14] A. M. Iuoras, S. I. Salcu, C. G. Rusu, C. Marginean, and P. D. Teodosescu, "Power factor compensation for a single-phase ACDC Hybrid Micro-Grid," in 2020 IEEE 11th International Symposium on Power Electronics for Distributed Generation Systems, PEDG 2020, Sep. 2020, pp. 455-458, doi: 10.1109/PEDG48541.2020.9244417.

[15] F. Wang, J. L. Duarte, and M. A. M. Hendrix, "Grid-interfacing converter systems with enhanced voltage quality for microgrid applicationconcept and implementation," IEEE Transactions on Power Electronics, vol. 26, no. 12, pp. 3501-3513, Dec. 2011, doi: 10.1109/TPEL.2011.2147334.

[16] A. Talebkhah, M. S. Shadlu, and S. Majid Fatemi, "Control Strategy of a Single Phase Active Power Filter with Adjustable DC Link Capacitor Voltage for THD Reduction in Non-linear Loads," in 2019 10th International Power Electronics, Drive Systems and Technologies Conference, PEDSTC 2019, Feb. 2019, pp. 606-611, doi: 10.1109/PEDSTC.2019.8697234.

[17] K. Kamel, Z. Laid, and K. Abdallah, "Mitigation of Harmonics Current Using Different Control Algorithms of Shunt Active Power Filter for Non-Linear Loads," Nov. 2019, doi: 10.1109/ICASS.2018.8652066.

[18] N. Prabhakar and M. K. Mishra, "Dynamic hysteresis current control to minimize switching for three-phase four-leg VSI topology to compensate nonlinear load," IEEE Transactions on Power Electronics, vol. 25, no. 8, pp. 1935-1942, Aug. 2010, doi: 10.1109/TPEL.2009.2036616.

[19] S. K. Asok, P. Baburaj, P. Jayaprakash, and C. M. Nirmal Mukundan, "Proportional Resonant Based Current Control of ThreePhase Single Stage Grid Connected PV System," in 2018 International Conference on Control, Power, Communication and Computing Technologies, ICCPCCT 2018, Mar. 2018, pp. 506-511, doi: 10.1109/ICCPCCT.2018.8574236.

[20] M. K. Islam, F. Haque, M. M. Islam, and K. A. Al Mamun, "Selective Harmonic and DC Offset Elimination in Grid Connected Single Phase Inverter by Using Optimal Controller and Modified EPLL," in 2018 International Conference on Innovations in Science, Engineering and Technology, ICISET 2018, Oct. 2018, pp. 184-189, doi: 10.1109/ICISET.2018.8745643.

[21] B. Jayachandra and A. Mahesh, "ANN Based Direct Power Control of 2-level PWM Rectifier," in 2018 International Conference on Power Energy, Environment and Intelligent Control, PEEIC 2018, Apr. 2019, pp. 623-627, doi: 10.1109/PEEIC.2018.8665617.

[22] A. Baliyan, M. Jamil, M. Rizwan, I. Alsaidan, and M. Alaraj, "An Intelligent PI Controller-Based Hybrid Series Active Power Filter for Power Quality Improvement," Mathematical Problems in Engineering, vol. 2021, pp. 1-10, Feb. 2021, doi: $10.1155 / 2021 / 6565841$. 
[23] "Introduction to artificial neural networks," in Proceedings - Electronic Technology Directions to the Year 2000, ETD 1995, 1995, pp. 36-62, doi: 10.1109/ETD.1995.403491.

[24] D. B. Thilakarathna, D. R. R. K. DIssanayake, D. M. K. V. B. DIssanayake, M. P. B. Ekanayake, G. M. R. I. Godaliyadda, and J. B. Ekanayake, "A Comparison between MPPT Algorithm and DC-DC Convertor Configurations for PV Systems," in 2021 10th International Conference on Information and Automation for Sustainability, ICIAfS 2021, Aug. 2021, pp. 327-332, doi: 10.1109/ICIAfS52090.2021.9605827.

[25] D. Ryu, Y. J. Kim, and H. Kim, "Optimum MPPT control period for actual insolation condition," in INTELEC, International Telecommunications Energy Conference (Proceedings), Oct. 2019, vol. 2018-October, doi: 10.1109/INTLEC.2018.8612419.

[26] K. V. Govardhan Rao \& P. Babu Rao, "A Novel Hybrid PV/FC Energy Management Scheme for Grid-Connection and Islanded Operation Capabilities," International Journal of Electrical and Electronics Engineering Research (IJEEER), vol. 4, no. 5. pp. 13-26, 2014, Accessed: Jan. 17, 2022. [Online]. Available: http://www.tjprc.org/viewarchives.php? year $=2014 \&$ id $=15 \&$ jtype $=2 \&$ page $=7$.

[27] O. Singh and S. K. Gupta, "A review on recent Mppt techniques for photovoltaic system," in 2018 IEEMA Engineer Infinite Conference, eTechNxT 2018, Mar. 2018, pp. 1-6, doi: 10.1109/ETECHNXT.2018.8385315.

[28] L. Alhafadhi and J. Teh, "Advances in reduction of total harmonic distortion in solar photovoltaic systems: A literature review," International Journal of Energy Research, vol. 44, no. 4, pp. 2455-2470, Dec. 2020, doi: 10.1002/er.5075.

\section{BIOGRAPHIES OF AUTHORS}
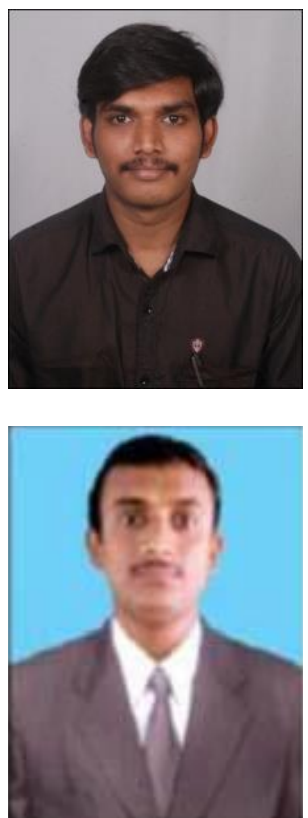

Mr. Kambhampati Venkata Govardhan Rao (iD 8d sc p Pursuing Ph.D. in Electrical Engineering at Koneru Lakshmaiah Education Foundation, Vaddeswaram, Guntur, India, Received Master of Technology from Abdulkalam Institute of Technological Sciences, JNTU Hyderabad, India in 2016, received Bachelour of Technology from Abdulkalam Institute of Technological Sciences, JNTU Hyderabad, India in 2014. His research interest includes Power Electronics, Power Systems. He can be contacted at email: kv.govardhanrao@gmail.com.

Dr. Malligunta Kiran Kumar (D) $8 \mathrm{SC}$ P received B. Tech Degree in Electrical and Electronics Engineering from Gokula Krishna College of Engineering and Technology, JNTU, Hyderabad, India, in 2007, M.E. Degree in Power Electronics and Drives from SreeSastha Institute of Engineering and Technology, Anna University, Chennai, India, in 2010 and Ph.D. in Electrical Engineering at Koneru Lakshmaiah Education Foundation, Guntur, India, in 2016. His research interest includes Switched Reluctance Machines, Power Electronics and Control Systems. He can be contacted at email: kiran.malligunta@gmail.com. 